\title{
AOR
}

Selected Papers of \#AolR2019:

The $20^{\text {th }}$ Annual Conference of the Association of Internet Researchers Brisbane, Australia / 2-5 October 2019

\section{BRIDGING, COACHING, AND BOUNDARY SPANNING: BROKERAGE AND INTERMEDIATION IN THE PHILIPPINE ONLINE PLATFORM LABOR ECONOMY}

\author{
Cheryll Ruth R. Soriano \\ De La Salle University, Manila \\ Earvin Charles Cabalquinto \\ Deakin University, Melbourne, Australia
}

The increasing networked connectivity and relative affordability of technology facilitated the rise of digitally-mediated service and microwork across the world. Workers, mostly located in the Global South, can now directly obtain 'gigs' through online labor platforms and microwork intermediaries such as Upwork, Onlinejobs.ph, or Freelancing.ph. The Philippines, the site of this study, is second to India in terms of the number of online platform workers actively involved in the market (Graham, Hjorth, and Lehdonvirta 2017, p.142). In the advent of abundant information infrastructures and 'flexible' work environments, it has been predicted that intermediaries will be bypassed in electronic markets as workers can do away with traditional hiring and employment procedures and connect to potential clients directly. Yet, we see an emerging category of digital labor intermediaries-locally called influencers, peer mentors, and coaches-- who are playing a significant role in the expansion and continued uptake of digital platform labor in the country. Building on and drawing connections between earlier works on the influencer economy (see for example Abidin, 2015; Senft, 2013; and Marwick, 2013) and on labor migration brokerage literature (Lin, Lindquist, Xiang, \& Yeoh, 2017; Shreshta \& Yeoh, 2018; Xiang, 2012), the paper conceptualizes digital labor brokerage arising within various 'spaces of (labor) intermediation.' We examine the transactional nature underlying the 'producer-audience' relationship of digital labor brokerage, the activation of trust and influence through personalised practices and mediated encounters, and the power dynamic underlying the digitally mediated symbolic and material power taking place between them and their respective teams as their audiences / partners. The paper seeks to contribute to the digital labor literature in two ways: 1) by characterizing the Suggested Citation (APA): Soriano, C.(2019, October 2-5). Bridging, coaching and boundary spanning: Intermediation and brokerage in the online labor platform economy. Paper presented at AolR 2019: The $20^{\text {th }}$ Annual Conference of the Association of Internet Researchers. Brisbane, Australia: AolR. Retrieved from http://spir.aoir.org. 
emergence of digital labor brokers in a labor supplying country in the global South, the role they play in the digital platform labor economy and the interventions that they engage; and 2) analyzing the structural conditions that facilitate the emergence of digital labor brokerage.

Drawn from a combination of participant observation in digital labor online groups and interviews with prominent coaches and digital workers, we present insights into the digital interventions that these brokers engage to wield influence by filling in critical structural gaps: a) coaching digital workers on the 'possibilities' of the digital labor economy, on how to address the structural ambiguities of digital labor platforms, on how to build 'marketable skills' to attract and sustain foreign clients, and on how to find 'good jobs' in these platforms, (b) aiding workers to span digital work boundaries and fluidly move across available platforms and job types to mitigate labor arbitrage; and c) bridge geographically dispersed workers that allow them to form a supportive online space where opportunities for labor are shared, exchanged, and debated. Finally, the paper examines the structural conditions that give rise to these brokers and how, in their role as influencers, they also set norms and standards in this largely unregulated sector, leading to fostering trust among their followers/partners and enabling them to benefit economically and socially in the process. In turn, we also consider how labor mobility or precarity is made possible and organized, through the work of digital labor brokers. We argue that they play a symbolic role in brokering the relationship between the local digital labor workforce and digital labor platforms, and between the digital workers and the state through various partnerships aimed at advancing the local digital labor economy.

Marketed as a geographically-flexible and competitive source of income, digital labor emerges as a highly attractive option in countries such as the Philippines where employment conditions are fraught with financial stagnation and socio-economic tensions and likewise celebrated by government as a viable solution to unemployment. Beyond attending to the unemployed, digital labor has also been attracting workers who experience difficulty in coping with the conditions surrounding older employment models such as business process outsourcing or call center work, overseas labor migration, or in supplementing casual and unstable employment elsewhere. We then posit that work displacement compels workers to embark in digital labor, and eventually build trust among co-workers through skills-matching, networking, and a reclaimed status, even symbolically. However, while workers generate profit from digital labor, research on digital worker experiences have shed light on the problematic realities of platform labor, which include increasing levels of anxiety over financial and career instability, physical stress, and isolation - all of which underscore the precarity that belie the optimistic facade of labor under the new economy (Hesmondhalgh and Baker, 2010, pp. 34-38; Graham, Hjorth \& Lehdonvirta, 2017; Lehdonvirta, 2016). These include exploitation as a result of 'labor arbitrage' practices by foreign clients and absence of bargaining power (Graham, Lehdonvirta, Wood, Barnard, Hjorth, and Simon, 2017, pp. 8, 11; Graham, Hjorth \& Lehdonvirta, 2017), as well as 'self-exploitation,' where workers work with long hours for fear of losing to competition or accept low rates in hopes of future advancement (Hesmondhalgh \& Baker 2011). 
Despite strong government pronouncements promoting digital labor as a crucial solution to unemployment, mechanisms for supporting workers remain absent. For labour migration, several private and public institutions have been set up to help workers aspiring to migrate overseas for jobs in terms of employment seeking, expectationsetting, salary identification, taxation, or welfare protection. For BPO-related jobs such as call center work, foreign companies operating in the country have institutionalized recruitment and employment mechanisms. By contrast, aspiring workers bid for jobs in labour platforms directly and many workers learn the ropes through experience of taking on gigs from different platforms. We argue that it is this dialectical tension of opportunity and precarity underscored by the neoliberal economy, shortcomings in state interventions for advancing the local labor condition, and a celebrity culture that presents the basis for the emergence of digital labor brokerage.

\section{References}

Abidin, C. (2015).Communicative intimacies: Influencers and perceived connectedness. Ada: A Journal of Gender, New Media, and Technology, 8, 1-16.

Graham, M., Hjorth, I. \& Lehdonvirta, V. (2017). Digital labour and development: Impacts of global digital labour Platforms and the gig economy on worker livelihoods. Transfer: European Review of Labour and Research 23(2), 135-162.

Graham, M., Lehdonvirta, V., Wood, A., Barnard, H. Hjorth, I. and D.P. Simon (2017). The risks and rewards of online gig work at the global margins. Oxford: Oxford Internet Institute Retrieved from https://www.oii.ox.ac.uk/publications/gigwork.pdf

Hesmondhalgh, D., \& Baker, S. (2010). A very complicated version of freedom: Conditions and experiences of creative labour in three cultural industries. Poetics, 38(1), 4-20. doi:10.1016/j.poetic.2009.10.001

Lehdonvirta, V. (2016). Algorithms that divide and unite: Delocalisation, identity and collective action in microwork. In J. Flecker (ed.) Space, Place and Global Digital Work: Dynamics of Virtual Work (pp. 53-80), London: Palgrave Macmillan.

Lin, W., Lindquist, J., Xiang, B., \& Yeoh, B. S. A. (2017). Migration infrastructures and the production of migrant mobilities. Mobilities, 12(2), 167174.doi:10.1080/17450101.2017.1292770

Marwick, A. (2013). Status Update: Celebrity, Publicity, and Branding in the Social Media Age. New Haven, CT: Yale University Press.

Senft, T. (2013). Microcelebrity and the branded self." In J. Burgess \& A. Bruns (Eds), A Companion to New Media Dynamics (pp. 346-54). Malden, MA: Blackwell.

Shreshta, T. and Yeoh, B. (2018). Practices of brokerage and the making of migration 
infrastructures in Asia. Pacific Affairs, 91(4), 663-672. ${ }^{1}$ 